dissociation thresholds-only the $v=0$ level of each state is observed and the rotational structure is truncated by predissociation. $^{7-10}$ Similarly, the REMPI spectrum of the F (4p) Rydberg state shows no vibrational progression. The modest resolution indicates that the lifetime of the F state is short.

One of the striking results of this study is the absence of the $\mathrm{D}^{2} \Delta\left(\nu_{00}=48510 \mathrm{~cm}^{-1}\right)$ and $\mathrm{E}^{2} \Sigma^{+}\left(\nu_{00}=52399 \mathrm{~cm}^{-1}\right)$ states from the REMPI spectrum. These states lie adjacent in energy to the F (4p) Rydberg state $\left(\nu_{\infty 0}=46700 \mathrm{~cm}^{-1}\right)$. Verma ${ }^{7}$ observed the D state with vacuum-UV spectroscopy and assigned it as a valence state with the electron configuration:

$$
\ldots(3 \mathrm{~s} \sigma)(3 \mathrm{p} \sigma)^{2}(3 \mathrm{p} \pi)^{2} \quad \mathrm{D}^{2} \Delta
$$

Herzberg et al. ${ }^{8}$ observed the D and E states with vacuum-UV spectroscopy and assigned them either to

$$
\ldots(3 \mathrm{~s} \sigma)(3 \mathrm{p} \sigma)^{2}(3 \mathrm{p} \pi)^{2} \quad \mathrm{D}^{2} \Delta, \mathrm{E}^{2} \Sigma^{+}
$$

which agrees with Verma's assignment, or to

$$
\begin{array}{ll}
\ldots(3 \mathrm{~s} \sigma)^{2}(3 \mathrm{p} \sigma)^{2}(3 \mathrm{~d} \delta) & \mathrm{D}^{2} \Delta \\
\ldots(3 \mathrm{~s} \sigma)^{2}(3 \mathrm{p} \sigma)^{2}(4 \mathrm{~s} \sigma) & \mathrm{E}^{2} \mathrm{\Sigma}^{+}
\end{array}
$$

The first assignment is to valence states and the second is to Rydberg states. In the REMPI spectrum these states would have appeared through two-photon allowed transitions at laser wavelengths of 412 and $382 \mathrm{~nm}$, respectively.

The differing number of laser photons required to ionize the $\mathrm{SiH}$ radical from each of its excited states may account for the presence and absence of REMPI bands. The $\mathrm{SiH}$ cations produced by excitation through Rydberg and valence states possess different electron configurations. $\mathrm{SiH}$ radicals which reside in the $\mathrm{F}(4 \mathrm{p})$ Rydberg state may ionize through the optical transition

$$
\begin{aligned}
\ldots(3 \mathrm{~s} \sigma)^{2}(3 \mathrm{p} \sigma)^{2} \ldots(4 \mathrm{p}) \operatorname{SiH}(\mathrm{F}(4 \mathrm{p})) \stackrel{\mathrm{e}^{-}}{\longrightarrow} \\
\ldots(3 \mathrm{~s} \sigma)^{2}(3 \mathrm{p} \sigma)^{2} \mathrm{SiH}^{+}\left(\mathrm{X}^{1} \Sigma^{+}\right)
\end{aligned}
$$

This ionization step (3) produces the $\mathrm{X}^{1} \Sigma^{+} \mathrm{SiH}$ cation and requires $17100 \mathrm{~cm}^{-1}$, i.e., no more than one laser photon. If the $\mathrm{D}$ and $\mathrm{E}$ states were Rydberg states, then they would also ionize to produce $\mathrm{X}^{1} \Sigma^{+}$cations through a process like (3). In this case we would expect the $D$ and $E$ states to produce measurable $2+1$ REMPI signals. In contrast, the valence state assignments of the $D$ and $E$ states imply that they ionize through the optical transition

$$
\begin{array}{rl}
\ldots(3 \mathrm{~s} \sigma)(3 \mathrm{p} \sigma)^{2}(3 \mathrm{p} \pi)^{2} & \mathrm{SiH}(\mathrm{D} \text { or } \mathrm{E}) \stackrel{\mathrm{e}^{-}}{\longrightarrow} \\
\ldots(3 \mathrm{~s} \sigma)(3 \mathrm{p} \sigma)^{2}(3 \mathrm{p} \pi) \mathrm{SiH}^{+}\left({ }^{1} \Pi \text { or }{ }^{3} \Pi\right)
\end{array}
$$

Ionization step 4 prepares an electronically excited cation. We estimate that (4) requires between 50000 and $80000 \mathrm{~cm}^{-1}$. To acquire this energy, $\mathrm{SiH}$ (D or $\mathrm{E}$ ) radicals must simultaneously absorb three or four photons; i.e., ion signals generated by resonances with the $D$ or $E$ valence states arise through $2+3$ or $2+4$ REMPI mechanisms. Compared to the one-photon-absorption rate, the rates for simultaneous absorption of three or four photons are very small. Thus, our laser can detect $\mathrm{SiH}$ radicals using a $2+1$ REMPI mechanism through the F (4p) Rydberg state but cannot detect $\mathrm{SiH}$ radicals using $2+3$ or $2+4$ REMPI mechanisms which involve the valence states. We conclude that the absence of the D and E states from the REMPI spectrum supports the previously proposed, valence state assignments.

\title{
Inclusion of Polyaniline Filaments in Zeolite Molecular Sieves
}

\author{
Patricia Enzel and Thomas Bein* \\ Department of Chemistry, University of New Mexico, Albuquerque, New Mexico 87131 \\ (Received: May 12, 1989)
}

\begin{abstract}
Polyaniline has been synthesized in the channels of mordenite (one-dimensional) and zeolite $Y$ (three-dimensional). Aniline was diffused from hexane solution into dehydrated zeolite pores containing different concentrations of framework hydroxyl groups. Addition of $\left(\mathrm{NH}_{4}\right)_{2} \mathrm{~S}_{2} \mathrm{O}_{8}$ to an aqueous suspension of the loaded zeolites afforded intrazeolite polyaniline chains, as demonstrated by FTIR, electronic absorption data, and recovery of the included polymer. Stoichiometric, kinetic, XPS, and microscopic data and the absence of bulk conductivity of the polymer/zeolite powders lead to the conclusion that the polymer is formed inside the host channel system. While the polyaniline chains in mordenite channels appear to be more highly oxidized than in Y zeolite, both systems show spectroscopic features typical of emeraldine base and emeraldine salt polymers. The polyaniline/zeolite hybrids represent a new class of materials containing synthetic conductors encapsulated in crystalline inorganic hosts with channel systems of molecular dimensions.
\end{abstract}

\section{Introduction}

The design and understanding of well-defined conducting structures of nanometer dimensions is one of the most challenging goals of contemporary solid-state science. In particular, fundamental studies of the electronic structure and conduction mechanism of conducting polymers ${ }^{1,2}$ would benefit greatly from such structures, and developments along this line could ultimately reduce the size of electronic circuitry to molecular dimensions. ${ }^{3,4}$ The goal of our research program in this area is to design cor-

(1) Handbook of Conducting Polymers; Skotheim, T. A., Ed.; Marcel Dekker: New York, 1986; Vol. 1 .

(2) Proceedings of the International Conference on Science and Technology of Synthetic Metals, ICSM 1988. Synth. Met. 1989, 28(1-3), 29(1).

(3) (a) Molecular Electronic Devices; Carter, F. L., Ed.; Marcel Dekker: New York, 1982. (b) Molecular Electronic Devices II; Carter, F. L., Ed.; Marcel Dekker: New York, 1987.

(4) Hopfield, J. J.; Onuchic, J. N.; Beratan, B. N. Science 1988, $241,817$. responding model systems via encapsulation of polymeric chain conductors in low-dimensional, ordered host lattices, particularly in zeolites. ${ }^{5}$ Confined charge-carrier systems are also of interest due to potential quantum-size effects on the electronic structure which have been observed in colloidal semiconductor systems, both in suspension and stabilized in zeolite host systems. ${ }^{6-8}$ Although there have been reports on the formation of conjugated polymers

(5) (a) Bein, T: Enzel, P. Beuneu, F : Zuppiroli, L Inorganic Compounds with Unusual Properties. Adv. Chem. Ser., submitted for publication. (b) Bein, T.; Enzel, P. Angew. Chem., submitted for publication. (c) Enzel, P. Bein, T. J. Chem. Soc., Chem. Commun., in press. (d) Bein, T.; Enzel, P Synth. Met. 1989, 29, E163.

(6) Moller, K.; Eddy, M. M.; Stucky, G. D.; Herron, N.; Bein, T. J. Am. Chem. Soc. 1989, 111,2564

(7) Herron, N.; Wang, Y.; Eddy, M. M.; Stucky, G. D.; Cox, D. E.; Moller, K.; Bein, T. J. Am. Chem. Soc. 1989, 111, 530.

(8) Parise, J. B.; MacDougall, J.; Herron, N.; Farlee, R. D.; Sleight, A W.; Wang, Y,; Bein, T.; Moller, K.; Moroney, L. Inorg. Chem. 1988, 27, 221. 
TABLE I: Zeolite/Aniline Samples

\begin{tabular}{|c|c|c|c|}
\hline samples $^{a}$ & $\begin{array}{l}\text { color of } \\
\text { product }\end{array}$ & $\begin{array}{l}\text { monomer loading } \\
\text { per unit cell }\end{array}$ & $\begin{array}{l}\text { surface capacity } \\
\text { per unit cell }\end{array}$ \\
\hline $\mathrm{Na}_{56} \mathrm{Y}-\mathrm{AN}$ & orange $^{b}$ & 43 & 0.2 \\
\hline $\mathrm{H}_{46} \mathrm{Na}_{10} \mathrm{Y}-\mathrm{AN}$ & deep blue & 31 & 0.2 \\
\hline $\mathrm{Na}_{8} \mathrm{MOR}-\mathrm{AN}$ & light orange ${ }^{b}$ & 5 & 0.06 \\
\hline $\mathrm{H}_{8}$ MOR-AN & blue & 3 & 0.06 \\
\hline
\end{tabular}

a Zeolite Y (Y), mordenite (MOR), sodium form ( $\mathrm{Na}-$ ), acid form $(\mathrm{H}-)$, aniline $(\mathrm{AN})$. Samples loaded with the aniline precursor were reacted with $\left(\mathrm{NH}_{4}\right)_{2} \mathrm{~S}_{2} \mathrm{O}_{8}$ in a water slurry for $2 \mathrm{~h}$ at $273 \mathrm{~K}$ and warmed to $295 \mathrm{~K}$ in $12 \mathrm{~h}$. b Unknown product; no polymer is formed. ' Saturation loadings were determined by difference from solution concentrations; the values can vary $( \pm 15 \%)$ depending upon treatment conditions. ${ }^{d}$ Estimated surface capacity for aniline, $1 \mu \mathrm{m}$ crystal size, normalized to molecules per unit cell.

in the presence of zeolites, the polymerization products appeared to be restricted to the zeolite crystal surfaces. ${ }^{9}$ Heteroaromatic polymer systems in larger scale host structures have been studied, including adduct formation of pyrrole with layered $\mathrm{FeOCl}^{10}$ or $\mathrm{V}_{2} \mathrm{O}_{5},{ }^{11}$ and polymerization of pyrrole in Nuclepore tunnel membranes. ${ }^{12}$

We report the first successful synthesis of single chains of polyaniline (PANI) within the crystalline channel systems of different large-pore zeolites. Zeolites are open framework aluminosilicates with pore sizes between 0.3 and $1.2 \mathrm{~nm}$, and exchangeable cations compensating for the negative charge of the framework. Zeolite $\mathrm{Y}$ is characterized by a three-dimensional open framework structure, composed of interconnected "sodalite" cages, while mordenite features a pseudo-one-dimensional 12-ring channel system. ${ }^{13}$ Both structures have an open pore size of about $0.7 \mathrm{~nm}$. The molecule-size channels of these hosts limit the thickness of polymer filaments to molecular dimensions.

\section{Experimental Section}

Zeolite host materials were derived from the sodium and ammonium forms of zeolite Y (LZ-Y52, LZ-Y62; Alfa) and of Na mordenite (Na-MOR; LZ-M5; Union Carbide). The ammonium form of MOR was obtained by refluxing $\mathrm{Na}-\mathrm{MOR}$ two times in excess of $0.1 \mathrm{M} \mathrm{NH}{ }_{4} \mathrm{Cl}$ for $15 \mathrm{~h}$. The zeolites were heated in a stream of oxygen $(1 \mathrm{~K} / \mathrm{min}, 10 \mathrm{~h}$ at $370 \mathrm{~K} ; 4 \mathrm{~h}$ at $670 \mathrm{~K})$ and evacuated for $2 \mathrm{~h}$ at $10^{-5}$ Torr followed by cooling, resulting in $\mathrm{Na}_{56} \mathrm{Y}, \mathrm{H}_{46} \mathrm{Na}_{10} \mathrm{Y}, \mathrm{Na}_{8} \mathrm{MOR}$, and $\mathrm{H}_{8} \mathrm{MOR}$ (subscripts indicate cations per unit cell). All subsequent steps were performed in a purified nitrogen atmosphere in a glovebox. Two grams of the dry zeolites was suspended in $50 \mathrm{~mL}$ of dry hexane, and aniline was slowly added under stirring at $295 \mathrm{~K}$, at a slight excess (10\%) relative to the pore capacity; see Table I. After stirring for 12 $\mathrm{h}$, the loaded zeolites were filtered off, washed, and dried on a filter membrane. One gram of the loaded zeolites was suspended in $25 \mathrm{~mL}$ of deaerated water at $273 \mathrm{~K}$, and an aqueous solution of $\left(\mathrm{NH}_{4}\right)_{2} \mathrm{~S}_{2} \mathrm{O}_{8}$ was added to the stirred suspension at a ratio of 1:4 oxidant:aniline. The suspension was stirred for $2 \mathrm{~h}$ at $273 \mathrm{~K}$ and then allowed to warm up to $295 \mathrm{~K}$ during $12 \mathrm{~h}$ and filtered off. It should be emphasized that no added acid is necessary for the polymerization to occur. The acidic zeolite samples turned deep blue after one to several hours during this treatment. Treatments with other oxidants resulted in unknown oxidation products $\left(\mathrm{H}_{2} \mathrm{O}_{2}\right)$ or did not afford oxidative coupling at appreciable rates $\left(\mathrm{O}_{2}\right)$, while an alternative precursor route ${ }^{5 \mathrm{~d}}$ (ion exchange with $\left[\mathrm{C}_{6} \mathrm{H}_{5} \mathrm{NH}_{3}\right]^{+} \mathrm{Cl}^{-}$, oxidation with $\left.\left(\mathrm{NH}_{4}\right)_{2} \mathrm{~S}_{2} \mathrm{O}_{8}\right)$ produced also

(9) Dutta, P. K.; Puri, M. J. Catal. 1988, /ll, 453.

(10) Kanatzidis, M. G.; Tonge, L. M.; Marks, T. J.; Marcy, H. O.; Kannewurf, C. R. J. Am. Chem. Soc. 1987, 109, 3797.

(11) Kanatzidis, M. G.; Wu, C.-G.; Marcy, H. O.; Kannewurf, C. R. J. Am. Chem. Soc. $1989,111,4139$.

(12) Polypyrrole fibrils with diameters between 0.03 and $1 \mu \mathrm{m}$ at $10 \mu \mathrm{m}$ length were produced. (a) Penner, R. M.; Martin, C. R. J. Electrochem. Soc. 1986, 133, 2206. (b) Cai, Z.; Martin, C. R. J. Am. Chem. Soc. 1989, 111, 4138 .

(13) (a) Breck, D. W. Zeolite Molecular Sieves; Krieger: Malabar, FL, 1984. (b) Szostak, R. Molecular Sieves. Principles of Synthesis and Identification; Van Nostrand Reinhold: New York, 1989.

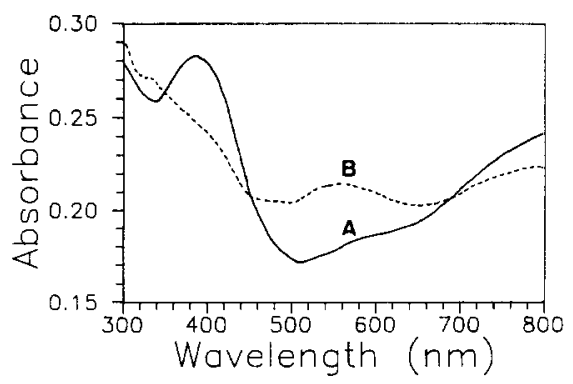

Figure 1. Electronic absorption spectra of zeolite/PANI samples dispersed in glycerol: (A) $\mathrm{H}_{46} \mathrm{Na}_{10} \mathrm{Y}-\mathrm{AN}$, (B) $\mathrm{H}_{8} \mathrm{MOR}-\mathrm{AN}$.

intrazeolite PANI. Bulk polyaniline ${ }^{14}$ was prepared by chemical oxidation of aniline with $\left(\mathrm{NH}_{4}\right)_{2} \mathrm{~S}_{2} \mathrm{O}_{8}$ in acidified water. Electronic absorption spectra of zeolite suspensions in glycerol were recorded with a Perkin Elmer 356 instrument, FTIR spectra of $\mathrm{KBr}$ pellets were taken with a Mattson Polaris spectrometer at $4 \mathrm{~cm}^{-1}$ resolution, and conductivity of pressed pellets was measured by the four-point probe technique. ${ }^{15}$ Pyrolysis mass spectra (up to 560 K) were taken with a Finnigan Mat 4500 Series instrument, and scanning electron micrographs were obtained on a Hitachi $\mathbf{S} 800$ microscope.

\section{Results and Discussion}

Polyaniline is a unique conducting polymer because its conductivity depends on both oxidative and proton "doping" levels. ${ }^{16}$ The chemical oxidation of aniline in acidic aqueous solution yields the "emeraldine salt" form of bulk polyaniline (PANI) as a dark blue-green precipitate, ${ }^{14}$ which is believed to consist (at the protonation level $0.5 \mathrm{H}^{+} / \mathrm{N}$ ) of equal numbers of reduced $\left[-\left(\mathrm{C}_{6} \mathrm{H}_{4}\right)-\mathrm{N}(\mathrm{H})-\left(\mathrm{C}_{6} \mathrm{H}_{4}\right)-\mathrm{N}(\mathrm{H})-\right]$ and oxidized, protonated quinone diimine repeat units, e.g., $\left[-\left(\mathrm{C}_{6} \mathrm{H}_{4}\right)-(\mathrm{H}) \mathrm{N}^{+}=\left(\mathrm{C}_{6} \mathrm{H}_{4}\right)=\right.$ $\left.\mathrm{N}^{+}(\mathrm{H})-\right] 2 \mathrm{Cl}^{-}$. In the channels of an acidic zeolite an analogous reaction is expected to occur, e.g.,

$$
\begin{gathered}
\mathrm{HY}+{ }_{n} \mathrm{C}_{6} \mathrm{H}_{5} \mathrm{NH}_{2} \stackrel{n \text {-hexane } / 295 \mathrm{~K}}{\longrightarrow} \mathrm{Y}\left(\mathrm{C}_{6} \mathrm{H}_{5} \mathrm{NH}_{3}\right)_{n} \\
\mathrm{Y}\left(\mathrm{C}_{6} \mathrm{H}_{5} \mathrm{NH}_{3}\right)_{n}+\left(\mathrm{NH}_{4}\right)_{2} \mathrm{~S}_{2} \mathrm{O}_{8} \stackrel{\mathrm{H}_{2} \mathrm{O} / 273 \mathrm{~K}}{\longrightarrow} \mathrm{Y}(\mathrm{PANI})
\end{gathered}
$$

If aniline is diffused into the different acidic zeolite forms and treated with the oxidant, the color of the resultant adduct changes from white to different shades of blue. In contrast, no polymerization is observed with the nonacidic $\mathrm{Na}$ forms of the zeolite hosts. ${ }^{17}$ Based upon the small surface capacity of the zeolite crystals (ca. $1 \mu \mathrm{m}$ diameter) and the high monomer uptake (Table I), it is clear that most of the monomer was introduced into the pore system of the zeolite host.

The electronic absorption spectra (Figure 1) of the blue samples $\mathrm{H}_{8}$ MOR-AN and $\mathrm{H}_{46} \mathrm{Na}_{10} \mathrm{Y}-\mathrm{AN}$ show absorption bands comparable to bulk PANI. ${ }^{18}$ The bands at ca. $560 \mathrm{~nm}(2.2 \mathrm{eV})$ have been associated with the quinone diimine structures of free base emeraldine polymer $\left[-\mathrm{N}=\left(\mathrm{C}_{6} \mathrm{H}_{4}\right)=\mathrm{N}-\right]$ obtained upon deprotonation of the salt with $\mathrm{NH}_{3}{ }^{19}$ In slightly acidic media, the $2-\mathrm{eV}$ absorption is observed as oxidation nears the $1 \mathrm{e}^{-} / \mathrm{N}$ level. ${ }^{19,20}$ Since the intrazeolite environment of the above samples is acidic, the presence of the 2.2-eV band must be associated with a high oxidation level of the polymer. The shoulders at approximately $400 \mathrm{~nm}(3.1 \mathrm{eV})$ and the broad features in the red and near-IR $(<1.8 \mathrm{eV})$ are associated with radical cations supporting polarons

(14) MacDiarmid, A. G.; Chiang, J. C.; Richter, A. F.; Somasiri, N. L. D.; Epstein, A. J. In Conducting Polymers; Alcacer, L., Ed.; Reidel Publications: Dordrecht, The Netherlands, 1986; p 105.

(15) Smits, F. M. Bell Syst. Tech. J. 1958, 37, 711

(16) Chiang, J. C.; MacDiarmid, A. G. Synth. Met. 1986, I3, 193.

(17) Small concentrations of an unknown orange oxidation product are sometimes formed. 165 .

(18) Epstein, A. J.; MacDiarmid, A. G. Mol. Cryst. Liq. Cryst. 1988, 160,

(19) Glarum, S. H.; Marshall, J. H. J. Phys. Chem. 1988, 92, 4210. (20) McManus, P. M.; Cushman, R. J.; Yang, S. C. J. Phys. Chem. 1987 91,744 . 


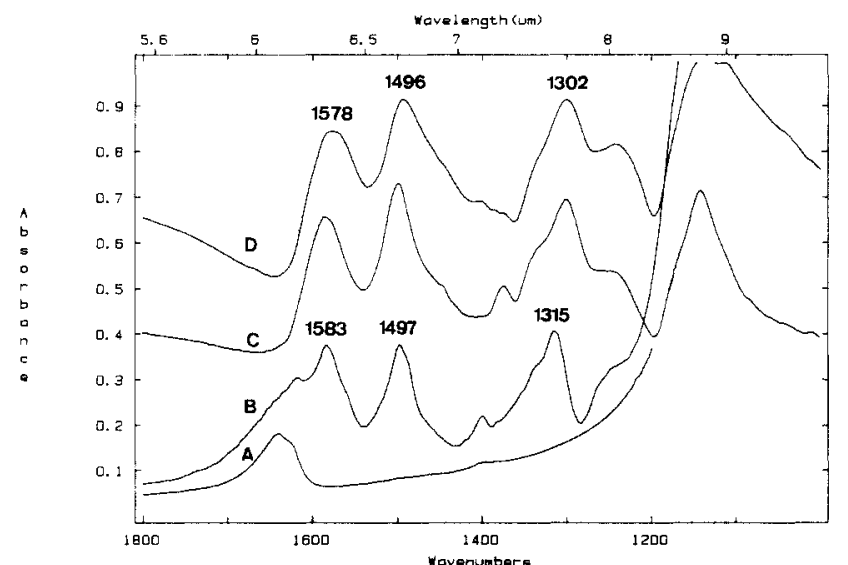

Figure 2. FTIR spectra of PANI samples: (A) $\mathrm{Na}_{56} \mathrm{Y}$, (B) $\mathrm{H}_{46} \mathrm{Na}_{10} \mathrm{Y}$ AN, (C) PANI extracted from $\mathrm{H}_{46} \mathrm{Na}_{10} \mathrm{Y}$-AN, (D) bulk polyaniline.

as charge carriers. ${ }^{18-20}$ These two features indicate the presence of (protonated) emeraldine salt and indicate the level of polymer oxidation: with higher degree of oxidation, the $1.5-\mathrm{eV}$ band moves to higher energies and the $2.9-\mathrm{eV}$ band reduces in intensity. ${ }^{19,21}$ The near-IR absorption of sample $\mathrm{H}_{46} \mathrm{Na}_{10} \mathrm{Y}$-AN is more redshifted and the absorption at $3.1 \mathrm{eV}$ is more intense than that of sample $\mathrm{H}_{8}$ MOR-AN, while the diimine feature $(2.2 \mathrm{eV})$ is more pronounced in the latter. These observatons indicate a higher degree of oxidation but less relative protonation of the polyaniline chains in the mordenite host. We note that the number and acidity of protons in mordenite are strongly affected by pretreatment conditions ${ }^{22}$ such that the available proton:aniline stoichiometry could actually be lower than in HY even though the overall initial proton:aniline ratio is slightly lower in the latter (Table I).

ESR data ${ }^{23}$ of the intrazeolite polyaniline show the presence of 0.0025 Curie-type spins per aniline loaded (comparable to bulk spin densities ${ }^{24,25}$ if the lower polymer yield in the zeolite is considered), with $g$ values ( $g=2.0034)$ characteristic of the bulk polymers. ${ }^{26}$

The infrared spectrum of sample $\mathrm{H}_{46} \mathrm{Na}_{10} \mathrm{Y}$-AN shows typical vibrations of the emeraldine salt form of polyaniline $\mathrm{e}^{21,27,28}$ at 1583 ,

(21) (a) Shacklette, L. W.; Wolf, J. F.; Gould, S.; Baughman, R. H. J. Chem. Phys. 1988, 88, 3955. (b) Monkman, A. P.; Bloor, D.; Stevens, G. C.; Stevens, J. C. H.; Wilson, P. Synth. Met. 1989, 29, E277.

(22) Meyers, B. L.; Fleisch, T. H.; Ray, G. J.; Miller, J. T.; Hall, J. B. J. Catal. 1988, 110, 82

(23) (a) ESR measurements of evacuated samples in sealed fused silica tubes were performed with a Bruker ER 200D instrument. (b) Bein, T.; Enzel, P.; Beuneu, F.; Zuppiroli, L., to be published.

(24) Pron, A.; Genoud, F.; Menardo, C.; Nechtschein, M. Synth. Met. $1988,24,193$.

(25) Nechtschein, M.; Genoud, F.; Menardo, C.; Mizoguchi, K.; Travers, J. P.; Villeret, B. Synth. Met. 1989, 29, E211.

(26) Javadi, H. H. S.; Laversanne, R.; Epstein, A. J.; Kohli, R. K.; Scherr, E. M.; MacDiarmid, A. G. Synth. Met. 1989, 29, E439.
1497, 1315, and $1246(\mathrm{sh}) \mathrm{cm}^{-1}$ (Figure 2), and a characteristic tail of the electronic excitation corresponding to free carrier absorption. The presence of the $1583-\mathrm{cm}^{-1}$ vibration indicates the dominant presence of quinone diimine radical cations. ${ }^{21,28}$ Small shifts between IR frequencies of the zeolite/polyaniline inclusions and bulk PANI suggest some interaction of the polymer with the host. The intrazeolite polyaniline can be recovered by dissolution of the zeolite framework with HF (from samples in HY, about $15 \%$ of the monomer loading are recovered as polymer). IR spectra of the agglomerated material are very similar to those of bulk polyaniline (Figure 2C,D).

The following observations demonstrate that the polyaniline chains are included in the channel systems of the zeolites. (i) The polymerization rate in the zeolite hosts is orders of magnitude slower than in solution reactions (MOR $<\mathrm{Y} \ll$ solution), indicating that the oxidant must diffuse through the channels to reach the intrazeolite aniline precursor. (ii) Polymerization takes place only in the presence of zeolitic protons which are available at significant levels inside the acidic zeolite crystals (no polyaniline is formed in the $\mathrm{Na}$ forms). (iii) XPS measurements show a homogeneous distribution of nitrogen throughout the zeolite crystals. (iv) The zeolite/polymer samples show no measurable "bulk" conductivity $\left(\sigma<10^{-8} \mathrm{~S} / \mathrm{cm}\right.$; no external polymer coating causing measurable conductivity is present on the zeolite crystals), while with zeolite samples deliberately covered with a thin film of PANI, $\sigma=10^{-6} \mathrm{~S} / \mathrm{cm}$. (v) No evidence for bulk polymer covering the surfaces of acid zeolite/PANI crystals is found in SEM images, while samples deliberately covered with PANI show distinct polymer features. (vi) Pyrolysis mass spectrometry shows no monomer evolution from the acid zeolite/PANI samples, in contrast to significant desorption of aniline from unpolymerized samples.

In conclusion, this study demonstrates that aniline in acidic zeolites can form intrazeolite polyaniline in oxidative polymerization reactions, in analogy to the oxidative coupling of aniline in acidic solution. While the level of intrazeolite acidity has a strong influence on the polymerization reaction, the nature of the channel system controls the degree of polymer oxidation which affects its electronic properties.

Our approach to decoupled "molecular wires" via intrazeolite polymerization is presently being extended to other organic conductors such as polypyrrole $\mathrm{e}_{\mathrm{a}, \mathrm{b}}$ and polythiophene. ${ }^{5 \mathrm{c}}$ The structural and transport properties of these and related systems will be reported elsewhere.

Acknowledgment. We acknowledge financial support from the National Science Foundation for instrumentation used in this work. We thank L. Zuppiroli and F. Beuneu (Ecole Polytechnique, Paris) for ESR studies and A. Galuska for XPS measurements.

(27) Sariciftci, N. S.; Bartonek, M.; Kuzmany, H.; Neugebauer, H.; Neckel, A. Synth. Met. 1989, 29, E193.

(28) Furukawa, Y.; Ueda, F.; Hyodo, Y.; Harada, I.; Nakajima, T.; Kawagoe, T. Macromolecules 1988, 21, 1297. 